\title{
Sufficient conditions for the existence of solutions for boundary value problems for fractional differential equations
}

\author{
Abdulkadir Dogan ${ }^{1}$ \\ ${ }^{1}$ Faculty of Computer Sciences
}

December 5, 2020

\begin{abstract}
In this article, we set up adequate circumstances for the existence of solutions for boundary value problems of fractional differential equations including the Caputo fractional derivative and nonlocal conditions.
\end{abstract}

\section{Hosted file}

mmas-paper-2020.pdf available at https://authorea.com/users/381361/articles/497220sufficient-conditions-for-the-existence-of-solutions-for-boundary-value-problems-forfractional-differential-equations 